\title{
Dialectics, Infant Shaking, and Perpetrator Statements in Child Maltreatment
}

\author{
Dean L. Biron PhD
}

\begin{abstract}
There is little middle ground in the dispute between those who believe violent shaking to be a cause of infant mortality and those who deny any link between the two. This brief report considers, from a philosophical perspective, the state of the infant shaking debate and the potential for a future dialectical resolution based on the available evidence. It is argued that for such a resolution to become a reality, it will be necessary for child protection professionals to work to combine a more inclusive, transdisciplinary attitude to research with a more rational, civil approach to dialogue.
\end{abstract}

\section{Keywords}

Physical abuse; Abusive head trauma; Child Maltreatment; Infant shaking; Dialectics; Perpetrator Statements.

Dialectical thinking, as associated with the German philosopher Georg Hegel (17701831), involves working rationally through oppositional concepts with the aim of transforming these into an improved solution or outcome. In present-day society there is an overwhelming turn, fuelled by political partisanship and a profiteering media, away from dialectics and toward forms of persistent, spiteful debate where conflicting arguments remain irreconcilable. The climate change issue is perhaps the outstanding example of this, with the global problems of pollution, deforestation and over- 
population doomed to persist in the face of an obstinate false opposition between "believers" and "deniers."

The violent shaking of infant children is another issue where the discourse remains stalled between two contradictory viewpoints. Amidst virtually unanimous acceptance of the ongoing social problem of child mortality and morbidity resulting from abuse and neglect, the question as to whether shaking can cause serious brain injury in small children appears to have no real middle ground. On the one hand, there is a majority group for whom the dangers of violent shaking have long been proven beyond any reasonable doubt. On the other, there is a smaller but vociferous number who see the idea that violent shaking can cause life-threatening injuries as unproven, if not impossible.

A series of assertions and counter-assertions published in the journal Minnesota Medicine in 2010 constitutes but one notable recent addition to this debate. On the antishaking side, a number of correspondents write to belittle the claims of researchers who assert that the accumulated evidence for shaking-related infant mortality is substantial. A letter by Kirk Thibault (2010), a biomechanical engineer with a long history of involvement in the debate, typifies the anti-shaking viewpoint, with its references to an absence in the literature of witnessed shaking events relevant to associated symptoms and the inability of experimental models to replicate the forces said to be required to cause brain injury.

Thibault's assertions are emblematic of an increasing number of published claims purporting to throw doubt upon the notion that shaking can lead to serious brain injury in infants (Donohoe, 2003; Geddes \& Plunkett, 2004; Leestma, 2006; Lowenstein, 2004; Orient, 2005; Squier, 2008; Yazbak, 2005). Gabaeff (2010), in the Minnesota Medicine exchange, go so far as to claim that the evidence for the defense "trumps the unsupported belief in this improbable and unproven construct of shaking" [emphasis added]. A conference being held in August 2011 in Vancouver, by an organisation titled Medical Misdiagnosis Research shows that this group of disputants is becoming more organized, as well as widening its purview by contesting myriad established views in child abuse research. One abstract for the conference, authored by a Dr. Horace B. Gardner, ophthalmologist, is titled: "Shaken baby: a syndrome that never was, never 
will be and never should have been" (www.medicalmisdiagnosisresearch. wordpress.com).

For their own part, those on the other side of this argument have recently sought to step back from use of the term "shaken baby syndrome" (Christian \& Block, 2009), acknowledging the need to avoid so-called "group character evidence" (Mosteller, 1996) by focusing more upon the facts specific to each individual case of potential abusive head injury. Physicians long associated with the diagnosis and investigation of infant shaking have adopted a more conciliatory tone in lamenting the dilemma of "duelling experts" (Reece, 2010) and asking those involved to engage in a more "civil dialogue" (Guthkelch: in Shapiro, 2011).

Everyone who has an interest in this matter has an opinion or a bias to declare, even if only to declare that they are unsure of the evidence. As a former police detective, I have little expertise to allow me decide on the basis of either the medical or the biomechanical science. My experiences investigating and researching this type of incident are tempered by a Rortian tendency - after pragmatist philosopher Richard Rorty (1931-2007) - to be sceptical of claims to universal truths whenever they arise. As such, I believe that the recent move to rescind from the term shaken baby syndrome is a long overdue step toward raising the level of the dialogue. This is particularly so when it is understood that the "triad" of intracranial haemorrhage, retinal haemorrhage and cerebral oedema in the absence of any other evidence - such as relevant perpetrator or witness statements, indications of previous abuse, or associated injuries such as bruising or fractures - must constitute only a relatively small percentage of suspected abusive head trauma cases. Using syndrome-based terminology to classify a cohort of offences or offenders unnecessarily complicates what is a straightforward legal concept: an act or omission on the part of one person that inflicts harm upon another. (See Freckelton [2005] on the inappropriateness of syndrome evidence in legal settings.) Always, the unique facts of the particular case under examination should remain the basis of any decision making, regardless of whatever general edicts individuals might embrace on the basis of their own experience and research.

Ultimately, two factors have weighed most heavily in cementing my belief that violent shaking can cause death and serious injury in infants and young children. The first 
relates to a specific epiphany: some years ago I took part in a biomechanical testing scenario where I was required to shake a doll, one incredibly lifelike in its representation of an infant child in appearance, size, weight and touch. Putting aside the scientific goals of the procedure - some of the findings from this work are discussed in Couper and Albermani (2008) - I came away from the experience convinced that the act is an inherently dangerous one, certain that only a few seconds of firm shaking could cause irreparable damage to the delicate brain of a tiny child.

The second is less intuitive. It arises from my knowledge that individuals across multiple jurisdictions consistently confess to violently shaking infants in circumstances where those children have been observed with symptoms associated with a severe underlying brain injury. The impossible hurdle for those who deny the potential lethality of infant shaking is this: every year, hundreds of adults make statements admitting to their maltreatment of small children, such maltreatment being wide-ranging both in type (how it is perpetrated) and outcome. The infant who is thrown against a wall and receives massive head injuries; the child who is intentionally neglected and dies from malnutrition; the baby who is stomped on and suffers a catastrophic abdominal insult; the child who is raped and left with horrific injuries as a result. In any of these cases, who would have cause - other than in those very rare instances where there is some suggestion that a confession has been improperly induced - to doubt a perpetrator statement that is supported by the medical evidence? The impossible leap of faith that some are asking us to take is to believe that confessions to shaking-type assaults for which there are no outwardly visible injuries, a relatively minor yet significant subset of all child abuse and neglect, are made either in error or under duress, whereas confessions to maltreatment resulting in overt injuries are rarely, if ever, disputed.

There has been only limited research into perpetrator statements in infant abuse. Smallscale descriptive reports (Biron \& Shelton, 2005, 2007; Bell et al., 2010) have been supplemented by more rigorous, larger-scale studies (Starling et al., 2004; Adamsbaum et al., 2010). Yet no-one has to date conducted a wide-ranging comparative study of perpetrator statements and associated medical evidence in all types of infant abuse and neglect. Given a large enough population from which to select, such a study could juxtapose significant numbers of non-impact abusive head trauma cases with myriad other types of infant and child maltreatment. It seems highly likely that this would lead 
to findings terminal to any argument that confessions to shaking-type maltreatment are somehow different to, or less reliable than, confessions to other types of abuse and neglect involving infants.

Those who assert that the anti-shaking spokespeople are irrelevant, that the science has already proven beyond doubt the link between shaking and mortality, are fooling themselves if they continue to believe that the issue is closed and the amassed clinical and research evidence will silence the naysayers. The notion that the pro-shaking lobby holds the scientific and moral high ground means little when transposed into an adversarial legal setting, with a significant number of abusive head trauma cases continuing to fail in court (indeed, often failing to even reach court). When Guthkelch says that "doctors need to be extra cautious when medicine reaches the courtroom" (in Shapiro, 2011), what he overlooks is that medical evidence, or for that matter any category of evidence, should always form part of a co-ordinated, transdisciplinary approach to investigating and, when warranted, prosecuting maltreatment committed against children. On that point, law enforcement and legal officers with the expertise in obtaining witness and confessional evidence and presenting it to a court have to date had barely any involvement in researching infant abuse and neglect. All interested parties - medical, legal, law enforcement - must take responsibility for the paucity of truly collaborative transdisciplinary research; it is crucial that this changes if further progress is to be made.

A well-known line from The Second Coming by Yeats reads: "Things fall apart; the centre cannot hold." It is a poem with many metaphorical allusions contrasting a stable centre with an unstable periphery. In a discursive context, the present (non-dialectical) fashion is very much to choose one side of an argument and stick to it. In such circumstances the centre cannot hold - it becomes a barren waste land across which shots are fired in an endless dispute between opposing forces.

Yet what is the central aim or favoured dialectical outcome in the infant shaking issue? It may be to view the term dialectic in Rorty's conception of "the attempt to play off vocabularies against one another" $(1989$, p. ). In that case some of the marginal voices should be integrated into the discourse, though not those which are patently malicious and have no application whatsoever to the issue at hand. It may more simply be a matter 
of working toward the goal of eliminating as far as possible both "the overdiagnosis and underdiagnosis of abusive head trauma" (Herman et al., 2011, p. 68).

The driving force in a discussion of this nature, as I would read it, must always be the welfare and safety of children, considered in concert with, though never subservient to, the broader rights and freedoms of all individuals. At present these twin fragments have broken away from the centre, and it would seem a necessary goal for all involved, no matter what their core beliefs, to think about how they can be reconnected dialectically in a way that moves this argument forward and toward a rational and socially beneficial outcome. The for and against dichotomy in infant shaking is in truth a spurious one that obscures a wealth of viewpoints which integrate child welfare and protection with the belief that an accused is always innocent until proven guilty.

Similar to climate change, where it would be absurd not to anchor any debate with acceptance of the indisputable fact that recent human activity has contributed negatively to our planet's environment, in the discourse on infant shaking I suggest that any sensible solution to the problem of protecting both vulnerable children and individual freedoms must begin by acknowledging that the violent shaking of an infant is an inherently dangerous act with the potential to cause severe and irreparable harm. Work to resolve this point beyond all reasonable doubt must proceed in concert with a determination to continue assessing each potential case of abusive head trauma on the merits of its collective evidence. Ultimately, only by pairing better quality research with a more civil, interactive dialogue is the standoff between "duelling experts" likely to be move forward from its present unseemly impasse.

\section{References}

Bell, E., Shouldice, M., \& Levin, A. (2011). Abusive head trauma: a perpetrator confesses. Child Abuse \& Neglect, 35(1), 74-77.

Biron, D., \& Shelton, D. (2005). Perpetrator accounts in infant abusive head trauma brought about by a shaking event. Child Abuse \& Neglect, 29(12), 1347-1358. 
Biron, D., \& Shelton, D. (2007). The functional time limit and onset of symptoms in infant abusive head trauma. Journal of Pediatrics \& Child Health, 43(1): 60-65.

Christian, C., \& Block, R. (2009). Abusive head trauma in infants and children. Pediatrics, $123,1409-1411$.

Couper, Z., \& Albermani, F. (2008). Infant brain subjected to oscillatory loading. Australian Journal of Mechanical Engineering, 6(2), 79-85.

Donohoe, M. (2003). Evidence based medicine and shaken baby syndrome - part I: literature review. American Journal of Forensic Medicine and Pathology, 24, 239-242.

Freckelton, F. (2005). Munchausen syndrome by proxy and criminal prosecutions for child abuse. Journal of Law \& Medicine, 12(3), 261-266.

Gabaeff, S. (2010). Flawed logic (Letter to the Editor). Minnesota Medicine, February, accessed 30 August 2011. Retrieved from

http://www.minnesotamedicine.com/PastIssues/PastIssues2010/February2010/LettersFeb2010.aspx

Geddes, J., \& Plunkett, J. (2004). The evidence base for shaken baby syndrome. British Medical Journal, 328, 719-720.

Herman, B., Makoroff, K., \& Corneli, H. (2011). Abusive head trauma. Pediatric Emergency Care, 27(1), 65-69.

Leestma, J. (2006). Shaken baby syndrome: do confessions by alleged perpetrators validate the concept? Journal of American Physicians \& Surgeons, 11(1), 14-16.

Lowenstein, L. (2004). Recent research and views on shaking baby syndrome. International Journal of Psychiatry, 34(2), 131-141.

Orient, J. (2005). Reflections on 'shaken baby syndrome': a case report. Journal of American Physicians \& Surgeons, 10(2), 45-50.

Reece, R. (2010). Highlighting violent and repetitive shaking. Pediatrics, 126, 572-573.

Rorty, R. (1989). Contingency, Irony and Solidarity.

Shapiro, J. (2001). Rethinking shaken baby syndrome. National Public Radio, 29 June 2011. Retrieved from http://www.essentialpublicradio.org/story/2011-06-28/rethinking-shaken-babysyndrome-3657 
Squier, W. (2008). Shaken baby syndrome: the quest for evidence. Developmental Medicine and Child Neurology, 50(1), 10-14.

Starling, S., Patel, S., Burke, B., Sirotnak, A., Stronks, S., \& Rosquist, P. (2004). Analysis of perpetrator admissions to inflicted traumatic brain injury in children. Archives of Pediatric and Adolescent Medicine, 158(5), 454-458.

Thibault, K. (2010). Biomechanical bias (Letter to the Editor). Minnesota Medicine, March, accessed 30 August 2011. Retrieved from

http://www.minnesotamedicine.com/PastIssues/PastIssues2010/February2010/LettersFeb2010.aspx

Yazbak, F. (2005). Post mortem on a 'shaken baby syndrome' autopsy. Journal of American Physicians \& Surgeons, 10(2), 51-52. 